\title{
POSSIBILITIES FOR IMPLEMENTING TELEWORK in Caras-Severin County
}

\author{
Dobrescu, M.; Costencu, M.; Dobrescu, C. \& Rudolf, C.
}

Abstract: The answer of the work market to the new challenges induces by the globalization process, by the technological, communication and actual IT changes is encompassed in the concept of telework. In this context the paper is about a research for identifying the possibilities for joining the work market through exploiting the opportunities offered by the new informatics and communication technologies and the training courses for implementing Teleworking. In a selective way, the conceptual frame is revealed from the adjacent literature that fundaments the research strategy in order to implement ta project for telework in the Carass-Severin county. One underlines the interest of the European Union and of the European Parliament for supporting and implementing telework, considering it a major direction in action and research. The research method is made up the inquiry based on a questionnaire and the answers to the questions reveal the degree of knowledge for the concept by the unemployed of the rural areas and their option for telework. One may realize that the responding persons accept this new form of work and the necessity for professional training in order to form the necessary competencies for their inclusion in the work market. Through the research, the needs have been identified on the acquisition of information and an educational offer has been established that is to be implemented in an environment auspicious to telework via the measures of administrative norms and specific social motivation. The research reveals the necessity of studies in the field of telework as this represents a new form of work in the context of an informational society.

Key words: telework, telecommuting, tele-nomadism, security, flexibility
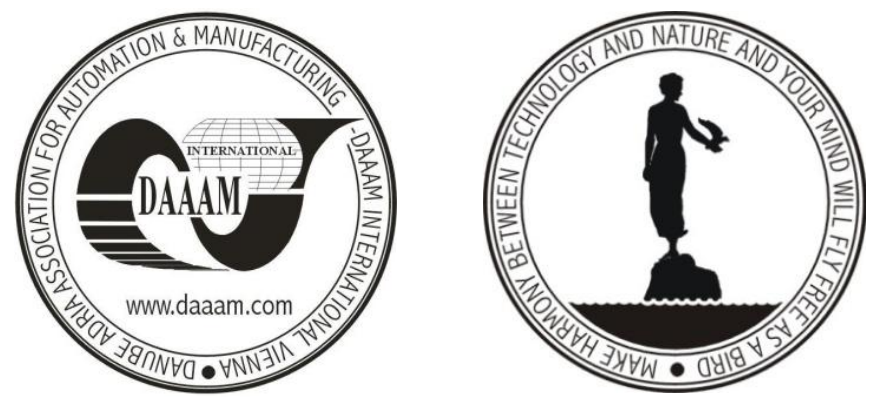

Authors' data: Conf. Univ. Dr. Dobrescu, M[ihail]; Conf.univ.dr. Costencu, M[irela]; Asist. Univ. Drd. Dobrescu, C[laudia]; Asist. Univ. Drd. Rudolf, C[ristian], University of Eftimie Murgu, P-ta Traian Vuia 1-4, Resita, Caras-Severin, dobrescumhl@yahoo.com, costencumirela@yahoo.com,dobrescu_cld@yahoo.com,rudi_ec@yahoo.de

This Publication has to be referred as: Dobrescu, M[ihail]; Costencu, M[irela]; Dobrescu, C[laudia] \& Rudolf, C[ristian] (2010). Possibilities for Implementing Telework in CarasSeverin County, Chapter 21 in DAAAM International Scientific Book 2010, pp. 203-218, B. Katalinic (Ed.), Published by DAAAM International, ISBN 978-3-901509-74-2, ISSN 1726-9687, Vienna, Austria

DOI: $10.2507 /$ daaam.scibook.2010.21 


\section{Introduction}

Telework in Romania represents a relative new concept that has appeared as a product of good practices in some countries of the European Union and of North America. In the same time, the debates have had as a source conceptual approaches of some specialists from the academic field. Thus, globalization, the underlined tendency of informational and techno-scientific development have brought into awareness this modern and flexible way of work by means of the telephone. As George M. Piskurich states, the interest for this concept appeared during the process of knowing tele-nomadism, at the beginning of the 1970s in the American CTC firm from California. Some organizations use the concept of flexible work to describe programs and processes that are not traditional and that are related to the concept of tele-nomadism. The flexible work place, in which people go about their activity may include the living space and is a part of tele-nomadism. The people who work in offices or far away centres, each day, yet are present only on a virtual level, without being nomads, in the proper sense of the term, may be considered as employed in telework centres. As Brian Clegg (1999) stated, telework is a socio-economic creation because: "innovation is applied to the idea of generation, (probably due to its new roots) especially when it comes to products, while creativity incorporates innovation as well as the task of solving problem..."

\section{Importance}

It is clear from both theoretical and practical perspective; the concept of Teleworking is not sufficiently debated in Romania. Thus, there is no theoretical support to provide benchmarks to base strategies in this area, and businesses have realized the benefits of new forms of work to streamline business and reintegration into the labour market interests of rural people without a job and unemployment existing agency records. The study is an initial research study to determine the needs of people unemployed in rural areas and bases the implementation of a strategy by making two telecenters and infrastructure, in which it will conduct training for participants to acquire skills for telework specific professions. The studies reveal telework advantages and disadvantages of having as a reference system to meet the economic and social dimension in general needs, without being centred on specific national and regional labour market. In this context, it is necessary to conduct field studies on local need for Teleworking identified linked to national and transnational companies, and considering best practices of countries that have implemented Teleworking.In the continuation of this study we proposed conducting research to establish awareness of the concept of Teleworking and the satisfaction of people and economic agents who practice this new form of work. The research strategy will underpin the expansion of telework in the Caras-Severin County. 


\section{Conceptual approaches regarding telework}

The general interest regarding the concept of telework appeared in the conditions generated by the oil crisis at the beginning of the 1970s. Jack Nilles from Southern California University has stated that the information technology (IT) was able to replace the physical movement through electronic communications, thus work being carried out at a distance. With the engagement of the general interest this flexible form of work has enjoyed much attention. It has also received an increasing number of definitions, firstly through theoretic founding and secondly through regulation.

Besides the term telework or Teleworking, introduced by the European Union authorities, firstly used by Jack Nilles and then by Francis Kinsman in his book Telecommuters of 1987, several definitions have appeared. The two terms: telecommuting and telework can be fond in Europe and the USA as well, with identical meanings. However, Jack Nilles, named the father of Teleworking offers an alternative definition by which a distinction is made between the two terms: "telecommuting means periodical work outside the office, one or several days a week, either at home, or at the customers home, or at his or her business residence. The work is done usually in a centre fitted with hardware specific to tele information, thus reducing or cancelling the transport to and from the workplace, regardless of the type of work contract". "Teleworking is the process that takes place the actual act of labour implies any form of substitution of the transport to and from the work place by using information technologies under the form of tele-communications and/ or computers. Thus labour is transferred towards the worker".

The authors is of the opinion that telecommuting is a form of Teleworking in the sense that it solves only the distance to the work place, but it is not a specific form of organization of labour such as Teleworking. Both definitions include the working from a distance assisted by information and communication technologies. The difference in the two terms is the management of transport and the derived purpose of the activities. If by telecommuting we approach the result of the labour to the client, by Teleworking or by telework the labour is transferred towards the actual performer of the task.

Taking into account the conceptual developing of telework and of good practices in some European countries, this concept was regulated in a Frame Agreement on telework S/2002/206.01.02, signed in Brussels in 2002, between social partners, without being inserted in the communitarian law by some directive. It has as a purpose to modernize the organization of labour, including flexible engagements and realizing the balance between flexibility and labour security (Tinca, O., 2003).

In accordance with art. 2, par. 1 of the above mentioned document, the individual work contract with the object of telework represents a form of organizing and realizing of labour by using informational technologies within the contract. The labour may take place equally, at the locations of the employer, but also at some other locations. From the analysis of the text one may note that the forms of distant labour may be classified in telework at home and outside the home. 
In Romania, telework is at an early stage of institutionalization, implementing, planning or researching of different programs. In a significant effort of implementing telework, we have undertaken a fundamental sociological research in the CarasSeverin county, based on the theoretical markers of the concept, taking as a target the unemployed people of the rural environment with the following objectives: identifying the level of education, formation and professional experience of the persons who make up the target group, identifying the needs, problems and grievances of the persons who make up the target group, issuing recommendations in regard to the structure of the program package of professional formation, issuing recommendations in regard to the best location for placing Tele-centres.

\section{Methodology of research}

The research method is similar to a diagnostic and consists on an inquiry based on a questionnaire. The research instrument used is the questionnaire made up of 22 questions. The questionnaire has been structured in 2 sections (identifying data and general data regarding the professional level and the options of the group). Filling out the questionnaire was done individually by each and every person. Whenever the need arose the subjects were aided by an operator during the period of collecting the data, namely February 2010. The choice for the research method is justified by the possibility for explaining the objectives and the accessibility of the subjects in responding to the questions of the questionnaire when the time permits them. In the mean time, the drafting of questions is founded on the specific of meeting the needs in economic, social and cultural dimension of the work market in regional and national context.

The area of research comprised 239 persons looking for a workplace, living in the rural environment, mainly aged between 17 and 35 .

The obtained results on this segment of the population reflect aspects worth knowing by a firm's management, without being generalized. The data was digitised using specific software. The final reports contain geographical and demographical data as well as the centralising of answers for each question. Also, the final reports have been exported in a program of table calculations in order to generate some useful graphics for the analysis.

\section{Data analysis and interpreting of results}

Human resource in terms of information society, are crucial for the development of a region and society in general. In this context, human resources in rural areas face difficulties in accessing education provision for skills training for employment for a job, but with reduced mobility due to the cost of transport.A solution to improve the situation of human resources in rural areas as Teleworking, which involves the use of telecommunications technology to replace completely or partially, travel to work and back home. Given the specific geographical, economic and social rural are of CarasSeverin, Teleworking should be accepted in response to the needs of human resources, rural issues, business issues and as a strategy for the management of 
transportation demand. With the absence of research in this field makes it difficult to design a coherent strategy for human resource development and implementation telework in Caras-Severin. The results of the research has immediate implications for social policy and would lead to more efficient matching of educational supply with human resource needs in specific skills training telework as a form of employment. The need of the study is given by the following realities that characterize rural labour Caras-Severin County:

- The existence of structural unemployment is mainly due to the economic system marked by certain imbalances which led to atypical development of the relationship between industry and the disappearance of others;

- The reactive attitude of the educational system and adapting the educational offer only classical forms of work and only when market demand is evident for certain specialties or skills. Bidders of educational market should be proactive, predicting the evolution of employment in terms of demand for certain skills to new forms of work;

The need to ensure medium and long term development of rural areas by introducing innovative techniques work, not affecting the rural environment and prevent young people tend to seek better paid jobs in urban areas.

The overall objective of the project is to facilitate employment and labour market conditions improved quality of life and work for at least 108 rural youth from CarasSeverin County through opportunities offered by new information technologies / telecommunications (here Teleworking), and courses training. The objectives of this research are: to identify the level of education, training and experience of people who form the target group; to identify needs, problems and grievances of people who form the target group, to issue recommendations on structure deck training programs that would help achieve the overall objective of the project, to make recommendations on the optimal location for placement of Telecenters. The analysis and interpretation of responses from subjects was performed at both geographic-and demographic questions in each part.

The distribution of unemployed people by unemployment agencies. Bocşa (20) Bozovici (41) Băile Herculane (45) Caransebeş (30), Moldova Nouă (35), Oraviţa (27) Oţelu Roşu (41): Total (239).

The distribution of unemployed people by localities. Included in the sample were 239 rural unemployed who are unemployment record of seven agencies in CaraşSeverin (Bocşa, Bozovici, Băile Herculane, Caransebeş, Moldova Nouă, Oraviţa and Oțelu Roșu).

Distribution of unemployed in the records of agencies is the table and chart above. The table and graph shows that in the 85 rural municipalities, the largest number of unemployed from rural settlements subordinated to unemployment agencies in Băile Herculane (45), Bozovici (41) and Oțelul Roșu (41). To other state agencies are as follows: Moldova Nouă (35), Caransebeş (30), Oraviţa (27) and Bocşa (20). Distribution analysis of unemployment for the 85 rural localities in 10 municipalities that have their home between $6 \mathrm{a}$ and 15 unemployed, and 75 localities in the dispersion is between one and five unemployed. 
The distribution of unemployed people by age criteria. Age range of the sample is between 17 years and 46 years. Analysis reveals that: the range of age 17 years - 18 years are three unemployed $(1.25 \%)$ between 19 years old - 26 years are 123 unemployed $(51.46 \%)$ within 27 years - 31 years are 40 unemployed $(16.74 \%)$ within 32 years - 35 years are 34 unemployed (14.22\%) within 36 years - 40 years are 11 unemployed $(4.60 \%)$ within 41 years- 46 years there are nine are unemployed $(3.76 \%)$.

Distribution of unemployed people by gender. Of the 239 unemployed, 118 are men $(49 \%)$ and 121 women $(51 \%)$, resulting in a balanced distribution on grounds of sex. Default is a sample with a priori determination having regard to the quality of existing unemployment in record unemployment agencies. Data analysis reveals that the sample meets the conditions for research objectives.

\section{Interpreting the questionnaire}

\subsection{Last graduated school.}

- 33answers representing 14\% for the variant "primary studies";

- 47 answers representing 19\% for the variant "vocational studies";

- 119answers representing 50\% for the variant "medium studies";

- 40 answers representing 17\% for the variant "superior studies";

The distribution of responses shows that training levels correlated with the distribution of settlements, distribution based on age and sex unemployed are basic parameters that generate the potential for adequate training for telework.

6. 2. What activities have taken place during or immediately after graduation studies in the field? (Multiple response)?

- 8 answers representing $3 \%$ for the variant „I have work as a volunteer without pay)";

- 57answers representing $\mathbf{2 3} \%$ for the variant „I have worked as a temporary employee";

- 93answers representing $37 \%$ for the variant „I have worked as a permanent employee";

- 85answers representing 34\% for the variant „I have not worked";

- 6answers representing 3\%for the variant „other activities during the studies and after graduation".

Most people have worked either as a permanent employee or temporary worker. As stated in the answers, one has the largest share jobs, but not missing any features of Computer operator, Inspector for Human Resources, Secretary, etc. Which are suitable for Teleworking business?It appears also there is a significant percentage of those who have not worked at all, worked or have voluntarily undertaken other activities. The existence of people who have worked previously, have now lost their jobs and are unable to obtain another, and there those who have not worked at all, creates the need for the training courses. 
6.3. Have you taken part in personal information courses?

- 63 answers representing $26 \%$ for the variant" Yes"

- 176 answers representing $74 \%$ for the variant "No"

At this question a significant number of unemployed people (176 means a rate of $74 \%$ of all respondents) did not participate in training courses, which justifies the need for organizing training courses.

6.4. What is the reason for not taking training courses? (Multiple response).

- 49 answers representing $25 \%$ for the variant " high cost";

- 44 answers representing $22 \%$ for the variant „organizing institutions difficult to reach";

- 7 answers representing $3 \%$ for the variant ,insufficient rigorous training”;

- 8 answers representing $4 \%$ for the variant „uninteresting fields of training";

- 8 answers representing $4 \%$ for the variant, ,the offered degree does not hold relevance on the work market";

- 27 answers representing $14 \%$ for the variant ,family problems";

- $\mathbf{1 0}$ answers representing $\mathbf{5 \%}$ for the variant ,I do not wish to take part";

- 46 answers representing $23 \%$ for the variant "other reasons";

These types of responses in an overall $61 \%$ relevant to justify the educational offer. Also, courses can be organized in rural areas and enabling participation implementing easier to learning with family responsibilities. Are significant and the 46 responses to variant other reasons, mostly they show willingness to participate in training courses, to take account of responses like: I did not have the opportunity, it was not the desired field, I was not given the chance, my desired subject was not featured, I have not had the possibility so far.

\subsection{What kind of training you have completed the last three years? (Multiple} response).

- 11 answers representing $15 \%$ for the variant ,informatics, PC literacy courses";

- $\mathbf{2}$ answers representing $\mathbf{3 \%}$ for the variant „foreign languages courses”;

- 5 answers representing $\mathbf{7 \%}$ for the variant "negotiation, communication courses";

- 1 answers representing $\mathbf{1 \%}$ for the variant „business administration courses";

- 7 answers representing $10 \%$ for the variant „primary accounting”;

- 46 answers representing 64\% for the variant ,other courses";

It appears that the responses recorded for 46 response option other courses. Although a significant percentage, attended courses related skills have made the labour market needs and has not been identified as work that needs human resources in rural areas. Of the 239 unemployed, 63 (26\%) followed the training courses, while $0.5 \%$ of total graduates of computer courses, language courses, communication / negotiation and management of business administration. The result is that 217 
respondents did not complete those courses. The responses to the question: 5 correlated with responses to questions. 3 and 4 reveals the possibility of forming educational offerings and cross-specific competencies for Teleworking: (IT, languages, communication / negotiation, business administration and accounting).

6.6. Choose the options best suited to describe the training: (multiple response).

- 31 answers representing $\mathbf{3 0 \%}$ for the variant "offers mostly useful information";

- 46 answers representing $45 \%$ for the variant "are necessary in order to get the desired job";

- 26 answers representing 25\% for the variant „represent and advantage while being evaluated in an interview";

- $\mathbf{0}$ answers representing $\mathbf{0 \%}$ for the variant ,are too long";

- 0 answers representing $0 \%$ for the variant "the information is too much and it is difficult to access";

- 0 answers representing $0 \%$ for the variant ,the time table is clogged";

The responses to this question reveal useful training courses resulting implication that respondent's awareness training expertise to enter the labour market. Therefore, the degree of acceptance of an offer is higher education.

6.7. What would you like to do in the future? (Unique answer).

- 187 answers representing $\mathbf{7 8 \%}$ for the variant „to look for a new work place";

- 32 answers representing $13 \%$ for the variant "to start an independent business";

- 16 answers representing $\mathbf{7 \%}$ for the variant „to continue my studies";

- 4 answers representing $2 \%$ for the variant ,others";

The responses to this question reveals concern for respondents to take a job as an employee, to initiate an income generating activity independently, but the desire to continue his studies and skills training. It confirms the results of Question No. 6 (choose options best suited to describe the training).

6.8. Which of the following statements do you think fits the situation you are in? I did not find employment because: (multiple responses).

- 215 answers representing $\mathbf{4 8 \%}$ for the variant, ,there are insufficient places on the work market";

- 41 answers representing 9\% for the variant "I do not have the desired knowledge and competences as required by the employer";

- 57 answers representing $22 \%$ for the variant "I do not have sufficient personal relationships";

- 30 answers representing 7\% for the variant „I do not know where and when to look for a job";

- 47 answers representing $10 \%$ for the variant "I am interested only in activities respecting the graduated studies"; 
- 19 answers representing $4 \%$ for the variant "I am interested only in activities on a determined periods";

The high frequency responses are contained in the response option: not enough jobs in the labour market (\% 48). Some percentage responses are relevant for this specific version telework, given the alternatives and no answers. 2, 3, 4 and 5 shows the need for vocational skills training through the acquisition of knowledge and skills related to labour market requirements, training in communication skills for networking, counselling in job search and becoming aware of the multi qualification through professional training courses.

\subsection{What have you undertaken of lately to find a work place?}

- 112 answers representing $35 \%$ for the variant „I have analyzed the work offers in the local press";

- 70 answers representing $22 \%$ for the variant „I have sent CVs and letters of intent to potential employers";

- 16 answers representing $5 \%$ for the variant „I have taken part in employment courses";

- 107 answers representing $\mathbf{3 4 \%}$ for the variant „I have appealed to an agency of recruitment and employment";

- 14 answers representing 4\% for the variant ,others";

This question has been answered in many ways, because it is important to know all subjects efforts for finding a job and they connect with responses to questions. 5, reveals the need for skills training linked to labour market requirements. The responses to variant no. 5 (others) prove the allegation, but an insignificant fraction. Also notable is the significant role it occupies agency (34\% of responses) as well as the manner in which to find a work place.

6. 10. What are for you the defining features of a work place?

- 221 answers representing 33\% for the variant ,salary, income”;

- 115 answers representing 17\% for the variant ,working conditions”;

- 21 answers representing 3\% for the variant, good reports with the colleagues";

- 32 answers representing 5\% for the variant "good reports with the superiors";

- 27 answers representing 4\% for the variant "possibility for improving personal aptitudes";

- 36 answers representing $\mathbf{5 \%}$ for the variant "possibility for accumulating knowledge and experience";

- 43 answers representing 7\% for the variant "working hours";

- 11 answers representing 2\% for the variant "possibility for travelling";

- 115 answers representing 17\% for the variant ,work place safety";

- 49 answers representing $7 \%$ for the variant, ,distance to the living area”.

Quantifying responses to this question is carried out by using ordinal scale. For each variant were calculated response coefficients of importance (1 - most important, 
10 least important) by the weighted average of responses. As a result, responses have been ordered in order of importance coefficients calculated values from largest to smallest.It follows that preferences are centred on salary / income, which is item 1 on a coefficient of 1.28. 2 positions, with a coefficient of 2.10 is the job security. The interval between first and second coefficient is less than 1. Following job security is regarded as important with salary/income. At a greater distance than the second position lie the working conditions.

6.11. In which of the following fields do you think you can get a job based on knowledge, skills, competencies and current experience? (Multiple response).

- 27 answers representing 5\% for the variant ,administration, public institutions";

- 0 answers representing $\mathbf{0 \%}$ for the variant ,architecture, design”;

- 49 answers representing $9 \%$ for the variant ,constructions”;

- 23 answers representing $4 \%$ for the variant ,finances, accounting”;

- 4 answers representing 1\% for the variant „IT hardware";

- 13 answers representing $2 \%$ for the variant „IT software”;

- $\mathbf{1}$ answers representing $\mathbf{0 \%}$ for the variant ,law j”;

- 21 answers representing 4\% for the variant „marketing”;

- 21 answers representing 4\% for the variant „human resources”;

- 35 answers representing $\mathbf{7 \%}$ for the variant ,secretary";

- 32 answers representing $6 \%$ for the variant „tourism”;

- 9 answers representing $2 \%$ for the variant ,management";

- 3 answers representing $\mathbf{1 \%}$ for the variant „media/publicity";

- 12 answers representing $2 \%$ for the variant „bancs, insurances”;

- $\mathbf{2 5}$ answers representing $\mathbf{5 \%}$ for the variant „education, culture”;

- 12 answers representing $2 \%$ for the variant "engineering";

- 74 answers representing $14 \%$ for the variant „sales";

- 77 answers representing $\mathbf{1 5 \%}$ for the variant ,trade”;

- 54 answers representing $10 \%$ for the variant ,public relations, clients;

- 30 answers representing $6 \%$ for the variant ,other areas”;

The responses to this question have a very high degree of scattering, which means that the respondents have responded very differently and in varying percentages cover all areas specified. Spread and cover the wide areas in a small percentage point to the need for new skills training for specific professions especially suited for telework.

6.12. In which of the following fields do you want to acquire new information?

- 40 answers representing $9 \%$ for the variant „management”;

- 36 answers representing $\mathbf{8 \%}$ for the variant „marketing”;

- 61 answers representing $13 \%$ for the variant „sales”;

- 51 answers representing $\mathbf{1 1 \%}$ for the variant ,accounting”;

- 41 answers representing $8 \%$ for the variant „IT"; 
- 27 answers representing $6 \%$ for the variant „secretary”;

- 31 answers representing 7\% for the variant „human resources”;

- 37 answers representing $\mathbf{8 \%}$ for the variant „administration”;

- 48 answers representing $10 \%$ for the variant ,public relations, clients";

- 53 answers representing $\mathbf{1 1 \%}$ for the variant "tourist services";

- 44 answers representing $9 \%$ for the variant „other fields";

The distribution of persons wishing to gain knowledge in areas listed as response options are presented as percentage above. Most of the answers, but not a high percentage compared with others, received sales, accounting, tourism services, customer relations, namely IT. These are found to be areas of concern from the standpoint of telework for respondents wishing to build competencies.

\subsection{What services would be necessary for this purpose?}

- 149 answers representing $34 \%$ for the variant ,informing”;

- 47 answers representing $11 \%$ for the variant ,orienting”;

- 27 answers representing $6 \%$ for the variant „educational counselling”;

- 31 answers representing 7\% for the variant „,career counselling”;

- 153 answers representing 35\% for the variant „professional forming, training";

- 28 answers representing $\mathbf{7 \%}$ for the variant „others";

The responses to this question reveals that a significant percentage of respondents consider necessary service training / training, but also information services. This question is correlated with the question 12 and the distribution of responses support the need for skills training for Teleworking.

\subsection{How do you characterize yourselves?}

The answers to this question present the results of self-esteem on self-concept components and confidence. Results show that all relevant items of self-esteem and are at best average. Is at low level 67 respondents representing 28\%. Studies in this area shows that not always a low self esteem is a predictor in obtaining results and also not strongly correlated with business performance. The answers to this question must be however appreciated taking into account the subjectivism of the responding people.

\subsection{Rate your knowledge of language by scores of 1-5.}

With regard to language skills, they decrease as the number of understanding; (listening - 322, Reading - 315) to talking; (participation in the conversation - 305 Oral Discourse - 300) and writing; (written expression - 297). Hierarchy in absolute and relative frequency of responses to the question of Foreign Languages is as follows:

\section{a. English:}

- Understanding: Listening -113 (47\%) read -110 (46\%)

- Speech: participation in conversation -107 (44\%), oral discourse -107 (44\%)

- Writing: written expression - 104 (43\%); 
Dobrescu, M.; Costencu, M.; Dobrescu, C. \& Rudolf, C.: Possibilities for Impleme...

\section{b. French:}

- Understanding: Listening -88 (36\%), reading -87 (36\%)

- Speech: participation in conversation -80 (33\%), oral discourse -80 (33\%)

- Writing: written expression - 80 (33\%);

\section{c. German:}

- Understanding: Listening -42 (17\%), reading -42 (17\%)

- Speech: participation in conversation $-43(17 \%)$, oral discourse $-42(17 \%)$

- Writing: written expression - 42 (17\%);

\section{d. Spanish:}

- Understanding: Listening -38 (15\%), reading -35 (14\%)

- Speech: participation in conversation -35 (14\%), oral discourse -35 (14\%)

- Writing: Written expression -34 (14\%)

\section{e. Serbian:}

- Understanding: Listening -16 (6\%), reading -16 (6\%)

- Speech: participation in conversation -17 (7\%), oral discourse -15 (6\%)

- Writing: Written expression -16 (6\%)

\section{f. Italian:}

- Understanding: Listening -11 (4\%), reading -11 (4\%)

- Speech: participation in conversation 10 (4\%), oral speech -8 (3\%)

- Writing: Written expression -8 (3\%)

\section{g. Hungarian:}

- Understanding: Listening $10(4 \%)$ read $10(4 \%)$

- Speech: participation in conversation -9 (3\%), oral speech -9 (3\%)

- Writing: Written expression $-9(3 \%)$

\section{h. Czech:}

- Understanding: Listening -2 (0.8\%) read -2 (0.8\%)

- Speech: participation in conversation $-2(0.8 \%)$ oral speech $-2(0.8 \%)$

- Writing: Written expression $-2(0.8 \%)$

\section{i. Rroma}

- Understanding: Listening $-2(0.8 \%)$ read $-2(0.8 \%)$

- Speech: participation in conversation $-2(0.8 \%)$ oral speech $-2(0.8 \%)$

- Writing: Written expression $-2(0.8 \%)$

It appears that English is the most popular, followed by the French and German are in order, Spanish, Serbian, Italian, Hungarian, Czech and Romanian. The last two languages are the least known. Items (listening, reading, conversation, oral speech and written expression) are expressed in levels of knowledge of 1-5. It când be found that English is known to all items in greater proportion on every level, than other languages. In a proportion of $34 \%$ the same situation is to be found at French. Since the proportions are homogeneous labour market requirements (according to a study conducted during 10/20/2009 to 11/10/2009 www.ejobs.ro site, the language skills required by firms $81.5 \%$ refers to the English), the formation of skills in English language proficiency for all items (listening, reading, conversation, oral speech and written expression). 
6.16. How often do you use the internet? (Unique answer).

- $\mathbf{7 7}$ answers representing $\mathbf{3 2 \%}$ for the variant ,daily";

- 16 answers representing 7\% for the variant „minimum 3times a week”;

- 15 answers representing $6 \%$ for the variant, ,weekly";

- 11 answers representing $\mathbf{5 \%}$ for the variant ,several times a month";

- $\mathbf{5 9}$ answers representing $\mathbf{2 5 \%}$ for the variant "occasionally";

- $\mathbf{6 1}$ answers representing $\mathbf{2 5 \%}$ for the variant „,not at all”;

The unique responses to this question reveal the distribution of time periods for computer use. The weights are shown above results show that $25 \%$ of respondents do not use no computer, minimum 30\% knowledgeable computer, $13 \%$ have average knowledge about computer use and $32 \%$ of respondents use the computer daily, which means concern for the use computer.Due to significant share of respondentsthat do not use, or use more than absolutely necessary computer training in computer skills, related to specific telework.

\subsection{Why use the Internet? (Multiple response).}

Provides multiple choice question answers, especially to reveal all activities related to Internet use. Responses to this question are multiple and correlated with question 16, revealing the concern of respondents in computer use. It follows that a total of 102 respondents (14\%) use the Internet for job search, 92 respondents (12\%)use the Internet to search for music, movies, games, and 80 respondents $(11 \%)$ use the internet only messenger / sms, 75 respondents (10\%) use e-mail, 55 respondents $(8 \%)$ search for classifieds and 51 respondents (8\%) search for information using various search engines. Only two respondents use Internet for banking transactions, any respondent does not read the RSS feeds, and only seven (1\%) respondents read the newsletter. In the response option other states that some respondents used the Internet to build website. A response to this question reveals the need for controlled orientation of respondents in computer use for business purposes.

\subsection{What is your level of computer literacy (multiple responses)?}

- answers representing 33\% for the variant "editing text (Word)";

- 69 answers representing 19\% for the variant „operating data bases (Excel, Access)";

- 35 answers representing $\mathbf{9 \%}$ for the variant ,programming”;

- 57 answers representing $\mathbf{1 5 \%}$ for the variant ,editing images, design”;

- 17 answers representing $\mathbf{5 \%}$ for the variant „others";

- 72 answers representing $19 \%$ for the variant „I do not know how to use the PC";

The multiple answers to this question correlate with responses to questions. 16 and 17 and shows a low computer literacy. The percentages on each level of computer literacy are shown above, but significant percentage of $19 \%$ accounting for 72 respondents, who do not know how to work on the computer. Correlation and distributions to questions $16,17,18$ reveal a small number of those who use the computer, as well as alow level of computer literacy. The percentages on each level 
of computer literacy are shown above, but significant percentage of $19 \%$ accounting for 72 respondents, who do not know how to work on the computer. Correlation distributions to questions $16,17,18$ reveals that those who use the computer, the operating levels known, use it more for leisure rather than business purposes.

\subsection{Have you heard of telework/ telecenters? (Unique answer).}

- 137 answers representing $\mathbf{5 7 \%}$ for the variant „,never”;

- 53 answers representing $\mathbf{2 2 \%}$ for the variant „,very vaguely";

- 31 answers representing $\mathbf{1 3 \%}$ for the variant „I have read about this topic in the newspapers or seen it on TV";

- 12 answers representing 5\% for the variant „I have spoken with friends, family about his topic";

- 6 answers representing 3\% for the variant „I have researched this topic as I was interested";

The question is to answer the unique and awareness of the concept of Teleworking. Of the respondents share calculated on each response option, it is clear that most respondents 137 (57\%) no concept of Teleworking, a rate of 22\% know very vague concept and only 6 respondents (3\%) have thorough knowledge about this concept because they were concerned. Thus a very high percentage, approximately $80 \%$ have no knowledge of Teleworking. Thus it results that actions are required for knowledge and awareness concepts and its benefits for rural or geographically isolated area.

6.20.Would you be interested to work in the provision of services in a telecenters?

- 20 answers representing $8 \%$ for the variant „little interested";

- 18 answers representing $\mathbf{8 \%}$ for the variant ,very vaguely";

- $\mathbf{5 0}$ answers representing $\mathbf{2 1 \%}$ for the variant „,so and so";

- 67 answers representing $\mathbf{2 8 \%}$ for the variant „largely interested";

- 84 answers representing $35 \%$ for the variant "hugely interested";

The responses to this question focused on respondents; on their interest to work in the provision of services in a telecenters, about $63 \%$ are very or greatly interested in this. Projection of future employment is generated mostly by the desire for a job generator salary / income, working conditions and job security, but also understands the concept and benefits telework explained in meetings with patients.

\subsection{Which is the field you want to work in the telecenters/from home?}

Frequency of responses to the question is heterogeneous, with a high dispersion, which shows the diversity of preferences of respondents work in the areas mentioned the price of Teleworking. The high frequency responses can be found in commerce (electronic), sales (telephone) and public relations, but also for other areas are showing increased interest. The high frequency response is reflected in the trade (electronic), sales (telephone) and public relations, but also for other high interest areas occurs. 
6.22. What do you think you could use for future professional? (Multiple response).

- 128 answers representing $\mathbf{2 5 \%}$ for the variant "to learn how to search for a new work place";

- 91 answers representing $18 \%$ for the variant, ,to find out how to start a new business";

- 143 answers representing $28 \%$ for the variant ,to improve my competences through professional forming courses";

- $\mathbf{8 9}$ answers representing $\mathbf{1 8 \%}$ for the variant "to be guided towards special trades demanded by the work market";

- 54 answers representing $11 \%$ for the variant "to be part of a group, network of young people that act in the search of work places";

The question the ways of meeting the needs for the performance of respondents. Shows concern for improving skills through training courses $(28 \%)$ and support the learning process for seeking a job (most likely through counselling). In a high percentage preference is to identify ways to start a business / self-employment, counselling specializations related to labour market requirements but also for participation in a support network to work for job search.

\section{Conclusions}

The conclusions of the report are formulated, taking into account two pillars that form the objectives of the research as well. One is the level of education, forming and professional experience that form the target group.

The level of education of the questioned unemployed is correspondent to the acquisition of knowledge through professional forming courses specific to telework, as $86 \%$ have graduated medium and upper professional studies and a significant percentage has worked as permanent employees or as part time employees. One may notice that some of the unemployed have worked as computer operator, as human resources inspector, as secretary etc., jobs specific to telework.

Thus, one may denote that there is human potential with a level of education, forming and experience specific with the forming courses suitable to telework. The other is the needs, problems, and grievances of the persons who form the target group. One may notice that an important share of those questioned wish to take part in courses of professional forming and realize the need for competencies in order to become present on the labour market as a worker or as the owner of a business. In the same time, the responding persons consider the professional forming courses important as they are an advantage in a job interview and the information is useful for building up competences.

Thus, the degree of acceptance for the educational offer is high. One may conclude that an important part of the responding persons manifest awareness in the search of a work place, but they realise that they do not have the aptitudes and the knowledge the employers are looking for. The acquisition of knowledge in the fields specific to telework is accepted (commerce, sales, IT, secretary, tourism, customers relations), thus the setting up of tele-centres is justified. 
The questioned persons have to the better part, at least minimum computer knowledge and are willing to learn more in this professional field. However, they do not posses sufficient information on the concept of telework but are willing to work in the service department of a tele-centre.

They accept the telework especially in the field of electronic commerce, telephonic sales, and public relations but also in other specific parts of telework. At the same time, the responding persons show preferences towards starting a business and even being part of a support network for the location of jobs.

The research reveals the possibility for implementing telework in the rural environment as a new form of labour, but also the necessity for carrying out some sociologic research that may found inclusion strategies on the work market, taking into account the demographic, economic, social and cultural context, which is existing in the target area. Continuing the re will be a great deal of research in order to establish the degree of awareness of the concept of telework and of the satisfaction of the citizens and of the economic agents who practice this new form of labour.

\section{References}

Clegg, B. (1999). Creativity and innovation for managers, Ed. ButterworthHeinemann, ISBN: 0-7506-4255-6, Oxford

Jackson, P.J. (1998). Teleworking international perspectives from telecommuting to the virtual organisation, Editura Rutledge London, ISBN: 0-415-17354-x, London

Lin, C. A.; Atkin D.J. (2007). Communication technology and Social change, Lawrence Erlbaum associates, Publishers London, ISBN: 978-0-8058-5613-20-8058-5613-7, London

Piskurich, G.M. (2007). An Organizational full Telenal Guide to Telecommuting. Setting up and running a successful telecommuter program, Publishers ASTD, ISDN: 1-56286-086-0, Alexandria

Tinca, O. (2003). Concerns for amplifying the social dialogue in the European Union, Commercial Law revue, Nr.5/2003, ISSN: 1220-8515 